\title{
TEMPERATURE AND PRESSURE MEASUREMENTS COMPARISON OF THE ALUMINIZED EMULSION EXPLOSIVES DETONATION FRONT AND PRODUCTS EXPANSION
}

\author{
A.Lefrancois, J-Y Grouffal, P.Bouinot \\ French Ministry of defense, DGA $\backslash$ DCE \\ Centre d'études de Gramat \\ 46500 Gramat - France
}

\author{
S.Mencacci \\ Nitrochimie - EPC group - RD Laboratory \\ Usine la dynamite \\ 13310 Saint - Martin de Crau - France
}

\begin{abstract}
The detonation efficiency of emulsion explosives with increasing aluminum contents and particle size is investigated by using pressure and temperature measurements, performed at the back of cylinder tests. The influence on the detonation front and the products expansion is presented. A delayed energy release is observed in the detonation products expansion.
\end{abstract}

Pressure measurements are made with carbon resistor gauges, which have been shown to provide a relatively inexpensive and direct method for such techniques. The temperature profiles are determined by a low cost large spectral range pyrometer. Preliminary plane shock waves experiments carried out at $14.5 \mathrm{GPa}$ on $4 \mathrm{~mm}$ thick NM and NM/Al targets are conducted at CEG to compare this pyrometer to a reference six-wavelength pyrometer. Experimental results are presented.

\section{INTRODUCTION}

The mining explosives industry makes extensive use of ammonium nitrate (AN) based systems. As a development of the AN fuel oil system, emulsion explosives contain the AN (oxidiser) in an almost saturated aqueous phase solution in contact with small lightly dispersed droplets of the fuel phase (oil). The emulsion is sensitised to shock initiation by the incorporation of gas bubbles. Emulsion explosives provide a low cost option for a variety of blast applications. As non-ideal high explosives, these materials display significant charge diameter effects and inertial confinement effects on detonation performance.

It is well known that the addition of aluminum enhances the performance of explosives. In order to increase the knowledge of aluminum combustions, detonation temperature and detonation pressure were measured for aluminized emulsion explosives with different aluminum content and aluminum particle size.

The experimental characterization of energy release in the detonation products expansion mainly by the aluminum oxidation has been the objective of this paper. Consequently, the appropriate aluminum content and particle size are optimized to reduce the cost while maintaining the energy release for the industrial production of emulsion explosives.

Two experimental techniques are described and validated to measure the detonation pressure and temperature profiles for emulsion explosives. Pressure measurements 
are performed with carbon resistor gauges. A large spectral range pyrometer is presented in reference to a six-wavelength pyrometer for temperature measurements.

Emulsion explosives are then compared by cylinder tests using these two complementary measurement techniques.

\section{MEASUREMENT TECHNIQUES}

\section{Pressure measurement technique}

Carbon resistor gauges have been shown in the past to provide a relatively inexpensive and direct method with a good accuracy for detonation pressure measurements [1]. The gauge is fabricated by coating the carbon resistor $(510 \mathrm{ohms}, 0.125 \mathrm{~W})$ into a suitable plastic material. When subjected to a strong shock wave, the gauge undergoes compression and the conductivity increases in proportion to the magnitude of the pressure. An electronic circuit provides a constant source voltage regardless of the load.

The pressure gauges are calibrated at Nitrochimie - EPC group with the following method. Unconfined cylinder tests are used to investigate a large pressure range 0.5 to 14 GPa with the combination of different ideal high explosives and inert materials at the back. A carbon resistor gauge is included on the bottom of the attenuator, see figure 1 .

As an application of these carbon resistor gauges, the pressure measurement of an emulsion explosive Nitram (a) without aluminum is presented figure 2 . The pressure gauge is implanted at the back of the charge. The result show a good accuracy for the continuous decrease up to $6 \mu \mathrm{s}$ with a calculation of Hydro 3D, which is a reactive hydrocode able to compute detonation wave [2].

After 6 first $\mu$ s, the difference between the measurement and the calculation is certainly due to a non appropriate equation of states of the gases for the calculation with Hydro3D.

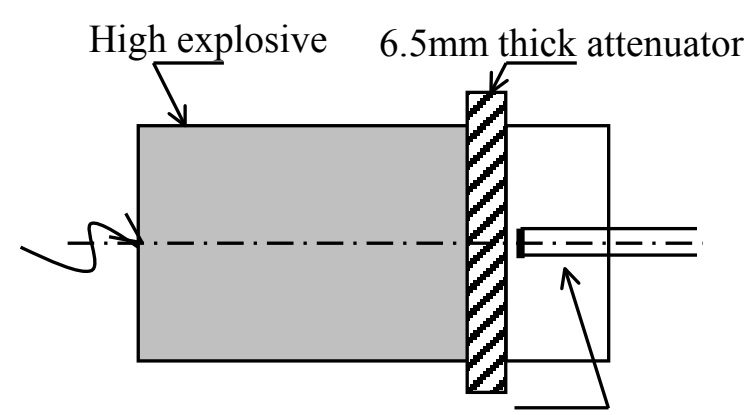

Carbon resistor pressure gauge

FIGURE 1. CALIBRATION SET-UP

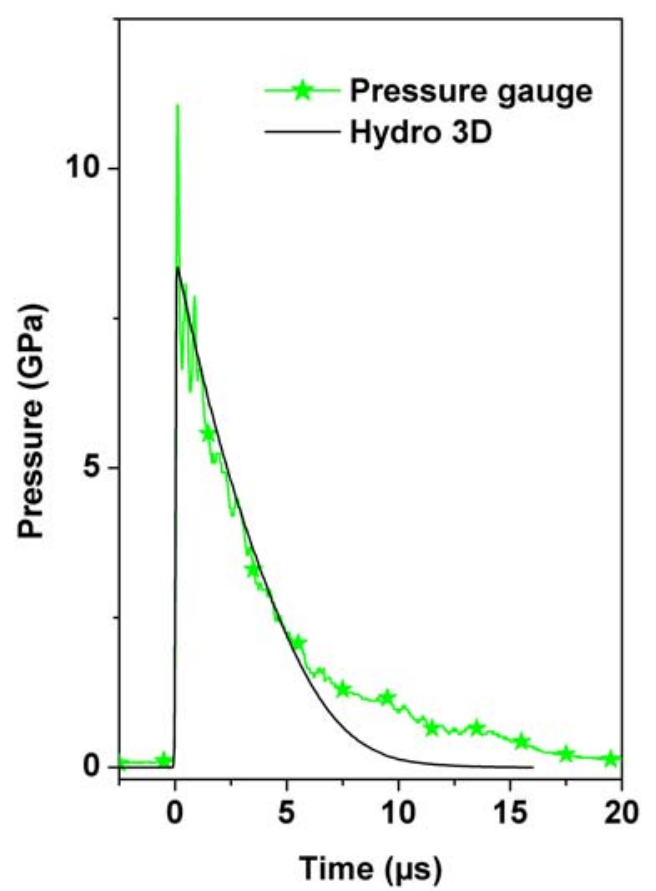

FIGURE 2. COMPARISON OF PRESSURE MEASUREMENT AND CALCULATION FOR NITRAM (A)

\section{Pyrometry techniques}

The temperature profiles are usually determined at CEG either by the sixwavelength pyrometer, or by a large spectral range pyrometer.

The time-resolved six wavelength pyrometer was developed in 1998 at CEG, and validated for measuring temperatures in detonation products of homogeneous and heterogeneous explosives [3,4]. The thermal radiation is collected from the emitting surface with a 
specific optical head, fiber and filters on photoelectric detectors. The six filters are selected to get a wavelength width equals to $40 \mathrm{~nm}$. The six selected wavelength are 500, $650,850,1100,1270,1570 \mathrm{~nm}$. A calibration is performed before each test using a blackbody Mikron M390 between $850 \mathrm{~K}$ and $3250 \mathrm{~K}$ to determine the proportionality between the electrical signals and the emitted luminances of the source. As the emissivity of the detonation front is unknown, the measured monochromatic luminances are used to fit the following law $L_{\lambda, T}=\varepsilon_{\lambda} \cdot L_{\lambda, T}^{0}$ using a polynomial form for the emissivity versus wavelength and a surface emissivity hypothesis. The results of this process are the emissivity versus the wavelength and the true temperature, which obtained over the range $1500 \mathrm{~K}-6000 \mathrm{~K}$ with a rise-time of $5 \mathrm{~ns}$.

Other pyrometers called the large spectral range pyrometers have been developed for a low cost with similar visible-near infrared photoelectric detectors as the six wavelength pyrometer. 12 large spectral range pyrometers are available at CEG, and could be used on the same experiment. This type of pyrometers is based on the principle of a proportional law between the electrical signal and the Planck's integral.

$$
\begin{aligned}
& V(T, \lambda, \varepsilon)=S \cdot \Omega \cdot \int_{\lambda} \varepsilon_{\lambda} \cdot L_{\lambda, T}^{0} \cdot \tau_{\lambda} \cdot r_{\lambda} \cdot d \lambda \\
& L_{\lambda, T}^{0}=\frac{C_{1}}{\lambda^{5}\left(\exp \left(\frac{C_{2}}{\lambda T}\right)-1\right)} \text { (Planck's law) }
\end{aligned}
$$

$\mathrm{S}$, seeing surface of the source $\Omega$, seeing angle of the source $\tau_{\lambda}$, transmissivity of the optical system, $r_{\lambda}$, spectral sensitivity of the detector, $\varepsilon_{\lambda}$, surface emissivity of the source.

The thermal flux is collected in a single spectral range [800 $\mathrm{nm}-1700 \mathrm{~nm}$ ] by a specific optical head and fiber with a risetime less than $20 \mathrm{~ns}$. A calibration, using the same blackbody Mikron M390 as previously over the range $850 \mathrm{~K}-3250 \mathrm{~K}$ is necessary to identify the proportionality between the voltage output and the Planck's integral.

As the emissivity of the detonation products is unknown, only the luminance temperature (temperature of a black body) is obtained directly from the large spectral range pyrometer measurements. The conversion to transform the luminance temperature into the true temperature is achieved by assuming the knowledge of the material emissivity.

\section{Plane shock waves experiments}

Plane shock wave experiments carried out on Nitromethane (NM) and NM/Al wt. \% 90/10 targets are conducted in a one-dimensional flow to compare the two pyrometers and validate the large spectral range pyrometer.

A single stage powder gun propels a tantalum projectile at a velocity of $2250 \mathrm{~m} / \mathrm{s}$ on the copper plate. NM or NM/Al explosives are confined in a polyethylene cylindrical chamber, enclosed by the copper plate. The experimental set-up is presented figure 3. The shock condition at $14.5 \mathrm{GPa}$ induces detonation in the explosive targets.

The thermal radiation of the detonation front and products expansion is collected throw two Lithium Fluoride observation windows. The measurements are performed at two points of the target back : the one for the six wavelength pyrometer and the other for the large spectral range pyrometer.

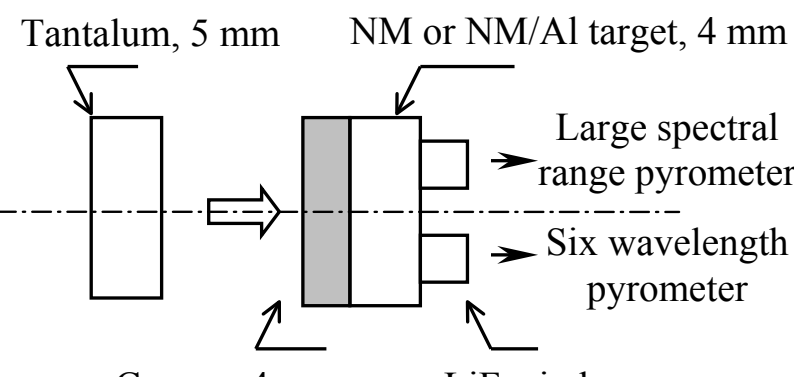

Copper, $4 \mathrm{~mm} \quad \mathrm{LiF}$ windows

\section{FIGURE 3. EXPERIMENTAL SET-UP OF THE PLANE IMPACT TESTS}

For NM target, the luminance temperature signals are presented figure 4 for the two 
pyromters. Only four channels among the six of the reference pyrometer are shown. The two channels $500 \mathrm{~nm}$ and $1270 \mathrm{~nm}$, which are not presented, are respectively similar to the channels below and above $1 \mu \mathrm{m}$.

These signals show chronologically:

- the propagation of the overdriven detonation,

- the propagation of the steady detonation,

- the interaction of the detonation products with LiF window, influenced by the heat conduction of the interface and semitransparent detonation products,

- the reloading due to the copper / detonation products interface

Before the interaction with the $\mathrm{LiF}$ window, absorption phenomena of NM affects similarly the signals of the channels beyond 1 $\mu \mathrm{m}$ and the signal of the large band pyrometer.

The correction of this phenomena has allowed to determine the luminances and luminance temperatures actually emitted by the steady detonation front.

$$
\begin{aligned}
& \mathrm{T}_{\text {lum }}(500 \mathrm{~nm})=3606+/-34.5 \mathrm{~K} \\
& \mathrm{~T}_{\text {lum }}(650 \mathrm{~nm})=3616+/-21 \mathrm{~K} \\
& \mathrm{~T}_{\text {lum }}(850 \mathrm{~nm})=3561+/-17.5 \mathrm{~K} \\
& \mathrm{~T}_{\text {lum }}(1100 \mathrm{~nm})=3468+/-40 \mathrm{~K} \\
& \mathrm{~T}_{\text {lum }}(1270 \mathrm{~nm})=3412+/-102 \mathrm{~K} \\
& \mathrm{~T}_{\text {lum }}(1510 \mathrm{~nm})=3384+/-193 \mathrm{~K}
\end{aligned}
$$

The computed true temperature of the six wavelength pyrometer is $3630 \mathrm{~K}+/-50 \mathrm{~K}$ for the steady state detonation, taking into account the absorption phenomena and the hypothesis of a surface emissivity with a linear form of the emissivity versus the wavelength. The emissivity value associated with the true temperature are :

$\varepsilon_{500 \mathrm{~nm}}=1 ; \varepsilon_{650 \mathrm{~nm}}=0.97 ; \varepsilon_{850 \mathrm{~nm}}=0.92 ;$

$\varepsilon_{1100 \mathrm{~nm}}=0.86 ; \varepsilon_{1270 \mathrm{~nm}}=0.83 ; \varepsilon_{1510 \mathrm{~nm}}=0.77$

The dispersion of the emissivity values is less than 0.1 .

The use of the surface emissivity hypothesis is discussed compared to the radiation transfer equation for $\mathrm{NM}$ in case of the steady state detonation.

From the knowledge of the six wavelength luminances and after the NM absorption correction, it is also possible to calculate the true temperature using the radiative transfer equation for a semi-transparent media in the case of the steady state detonation [5]. A linear form versus the wavelength is taken for the absorption coefficient $K_{\lambda}$. The computed true temperature is $3663+/-55 \mathrm{~K}$. The associated transmissivity values ( $\tau_{\lambda}=\exp \left(-\mathrm{K}_{\lambda} .1\right), 1$ is the depth of the cell) of the detonation products are :

$\tau_{500 \mathrm{~nm}}=0.075 ; \tau_{650 \mathrm{~nm}}=0.09 ; \tau_{850 \mathrm{~nm}}=0.113$;

$\tau_{1100 \mathrm{~nm}}=0.153 ; \tau_{1270 \mathrm{~nm}}=0.187 ; \tau_{1510 \mathrm{~nm}}=0.248$

The dispersion of the transmissivity values is less than 0.01 .

The two calculations of the true temperature and emissivity $\left(\varepsilon_{\lambda}=1-\tau_{\lambda}\right)$ for the steady state detonation give similar results (radiative transfer equation or surface emissivity hypothesis). Therefore, the hypothesis of a surface emissivity is justified for the six chosen wavelength [4].

For the large spectral range pyrometer, the luminance temperature is $3400 \mathrm{~K}$, similar to the one of channels beyond $1 \mu \mathrm{m}(1100 \mathrm{~nm}$, $1270 \mathrm{~nm}, 1510 \mathrm{~nm})$. The dispersion of the luminance temperature is less than $3 \%$. And the calculated true temperature of the steady state detonation front is $3556 \mathrm{~K}$, taking into account a emissivity of 0.85 . The difference of the true temperature is about $100 \mathrm{~K}$ with the six wavelength pyrometer.

The hypothesis of a surface emissivity for the steady state detonation is also validated for the large spectral range pyrometer.

The interaction time of the detonation products with $\mathrm{LiF}$ window is shifted by $74 \mathrm{~ns}$ for the large spectral range pyrometer, due to a possible dimensional deviation at the back of the polyethylene chamber, enclosed by the two LiF windows. The luminance temperature of the large spectral range is lower of more than $140 \mathrm{~K}$ compared to the other ones of the six wavelength pyrometer. 
The heat conduction affects the signals similarly, so this result show that the semitransparent detonation products have absorption bands in the large spectral range $800-1700 \mathrm{~nm}$. For the NM detonation products, the hypothesis of a surface emissivity is not working for a quantitative analysis, although the profile is reproduced.

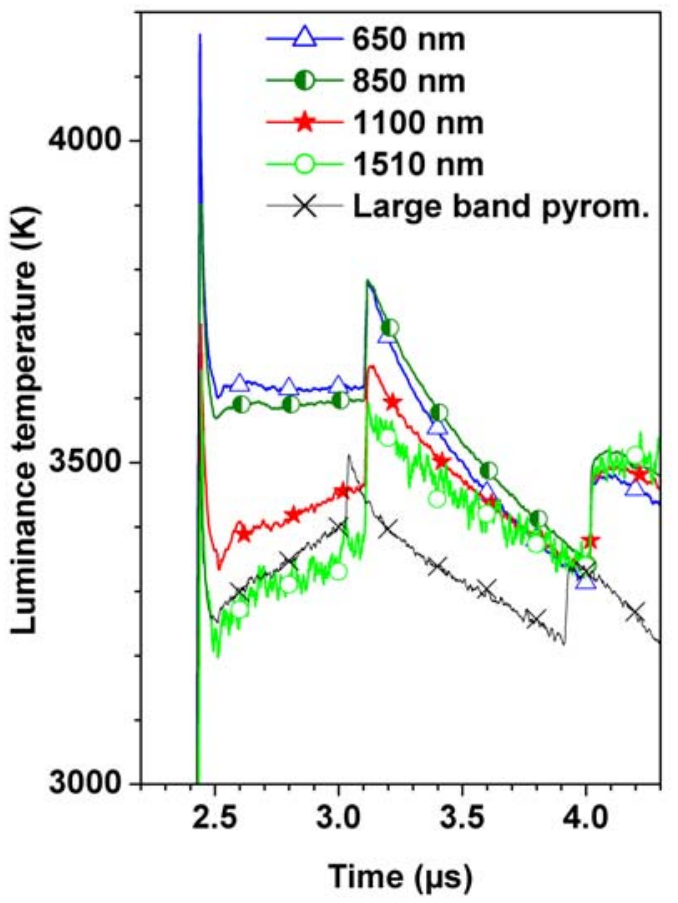

FIGURE 4. COMPARISON OF THE TWO PYROMETERS FOR NM

For NM/Al target, the luminance temperatures are presented figure 5 for the two pyrometers.

Because the NM/Al is opaque, these signals do not display the propagation of the steady detonation. Otherwise, the several phases of the signals are the same as for NM plane impact test.

The entry shock at the explosive/LiF window interface of the two pyrometers is shifted by $160 \mathrm{~ns}$, due to a measured impact tilt of 5 mrad (only $1.25 \mathrm{mrad}$ for NM target) and a possible dimensional deviation at the back of the polyethylene chamber, enclosed by the two LiF windows. Consequently, the arrival time of the reloading is also different of 110 ns (97 ns for NM target).

Except the arrival time differences, the luminance temperature of the large spectral range pyrometer is quite superposed with the channel $650 \mathrm{~nm}$, which is near to the computed temperature.

This result shows the validation of the large spectral range pyrometer for temperature measurement of $\mathrm{NM} / \mathrm{Al}$ detonation products using a surface emission hypothesis. Unlike $\mathrm{NM}$ alone after the interaction with the $\mathrm{LiF}$ window interface, the $\mathrm{Al}$ content allows a higher and continuous emissivity versus the wavelength, near the emissivity of a black body.

So, the large spectral range pyrometer can be applied to the study of aluminized emulsion explosives.

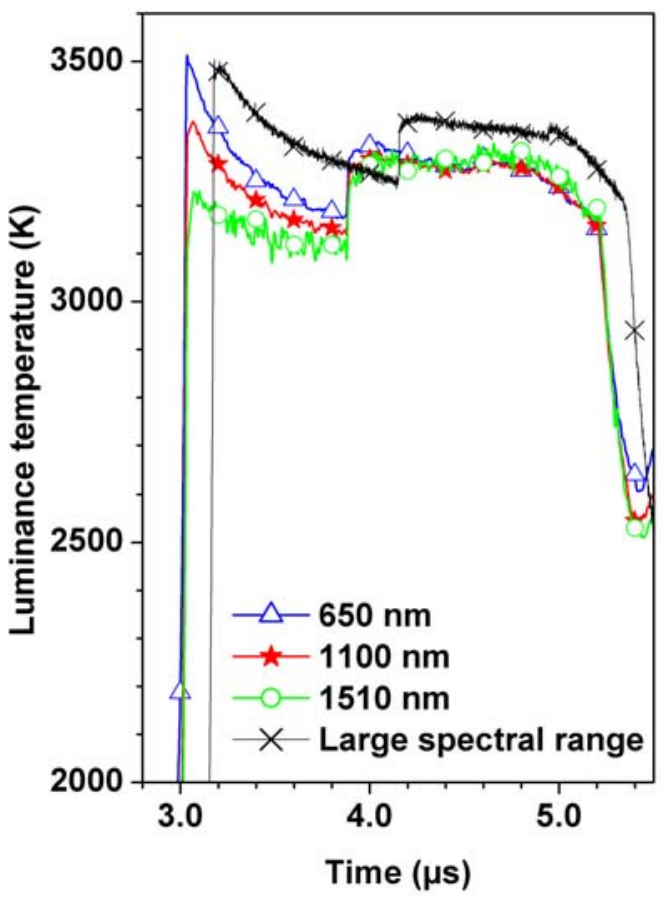

FIGURE 5. COMPARISON OF THE TWO PYROMETERS FOR NM/AL

\section{CYLINDER TESTS}

\section{Experimental set-up}

Four emulsion explosives, listed table 1 and manufactured at Nitrochimie - EPC group, are chosen for the experiments. They are based on ammonium nitrate, water and oil systems. The Al content is varied up to $14 \%$, and two types of $\mathrm{Al}$ powder additives are 
used for the compositions : fine and coarse particle sizes.

\section{TABLE 1. TESTED EMULSION EXPLOSIVES}

\begin{tabular}{|c|c|c|c|c|}
\hline Emulsions & $\begin{array}{c}\text { Nitram } \\
\text { (a) }\end{array}$ & $\begin{array}{c}\text { Nitram } \\
\text { (b) }\end{array}$ & $\begin{array}{c}\text { Nitram } \\
\text { (c) }\end{array}$ & $\begin{array}{c}\text { Nitram } \\
\text { (d) }\end{array}$ \\
\hline $\begin{array}{c}\text { Al content } \\
\text { [wt. \%] } \\
\text { Particule size }\end{array}$ & - & $\begin{array}{c}7 \% \\
\text { Fine }\end{array}$ & $\begin{array}{c}7 \% \\
\text { Coarse }\end{array}$ & $\begin{array}{c}14 \% \\
\text { Fine }\end{array}$ \\
\hline Compositions & \multicolumn{3}{|c|}{ AN, water, oil systems, etc ... } \\
\hline Density (g/cm $\left.\mathbf{c m}^{3}\right)$ & \multicolumn{3}{|c|}{1.20} & 1.28 \\
\hline $\mathbf{V}_{\text {deto }}(\mathbf{m} / \mathbf{s})$ & \multicolumn{3}{|c}{05000} \\
\hline $\mathbf{W t ~ ( k g ) ~}$ & \multicolumn{3}{|c}{0.7} \\
\hline
\end{tabular}

Cylinder tests are performed with either pressure or temperature metrology. For the pressure measurements, pressure gauges are implanted directly at the back of the emulsion explosives, see figure 6 .

For the temperature measurements in detonation products, the experimental set-up is presented figure 7 . The luminance temperatures are determined with one large spectral range pyrometer, at the back of the cylinder.

The large spectral range pyrometer is calibrated as previously with the PMMA window using the black body Mikron M390 over the range $850 \mathrm{~K}-3250 \mathrm{~K}$.

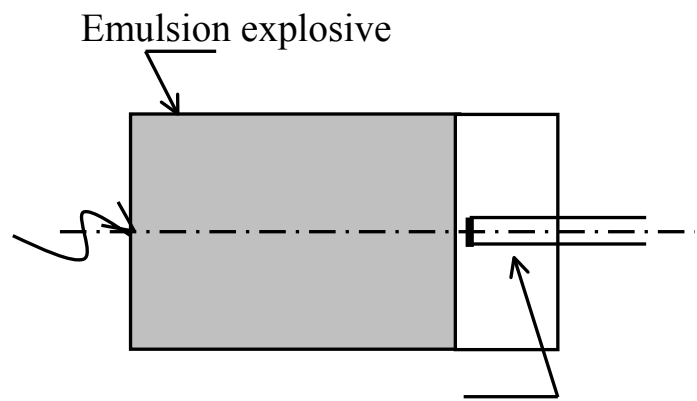

Carbon resistor pressure gauge

FIGURE 6 : PRESSURE MEASUREMENT EXPERIMENTAL SET-UP

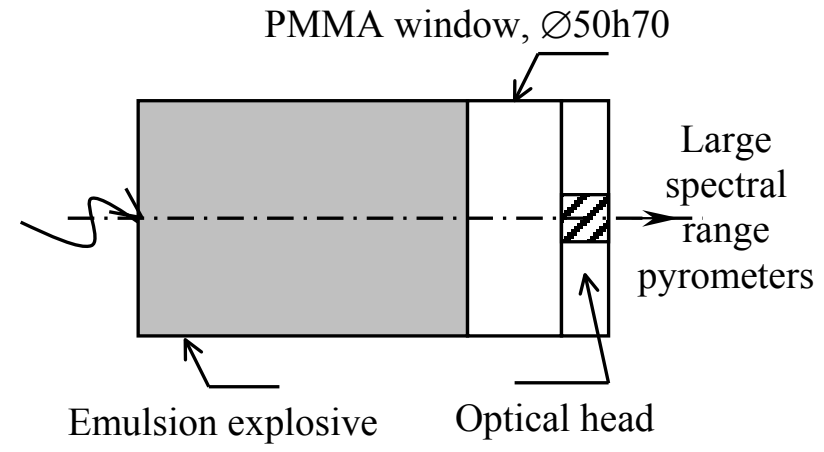

FIGURE 7. TEMPERATURE MEASUREMENT EXPERIMENTAL SET-UP

\section{Pressure measurements}

The pressure measurements are presented figure 8. The emulsion Nitram (a) is characterized by a continuous decrease of the pressure after the maximum value. While increasing the content of aluminum in the emulsion explosives, we observe a second maximum in the pressure signals, few microseconds after the detonation front ( $4 \mu \mathrm{s}$ for Nitram (d), $6 \mu$ s for Nitram (b)).

These maximums are very surprising, especially for composition Nitram (d). We have made 5 tests in the same conditions with the 3 products and every times the same type of signals are observed.

Temperature and pressure signals should be compared to explain this phenomena.

\section{Temperature measurements}

The luminance temperatures of the tested compositions are presented figure 9 .

The thermal flux of composition Nitram (a) is measured before the interaction of the emulsion with the PMMA windows, so this composition is identified as semi-transparent. The detonation front luminance temperature is higher for Nitram (a) with $4179 \mathrm{~K}$, then comes Nitram (b) with $3340 \mathrm{~K}$, then Nitram (d) with $3054 \mathrm{~K}$, and finally Nitram (c) has the lowest luminance temperature with 2703 $\mathrm{K}$. 
After the interaction of the detonation products with the PMMA window, Composition Nitram (d) reveals a higher second maximum, which occurs $5 \mu$ s after the shock entry. Higher is the Al content, higher is this delayed maximum of the luminance temperature. Fine aluminum particles play also a major role in the formation of this maximum, because Nitram (c) contaning coarse $\mathrm{Al}$ particles does not show any effect.

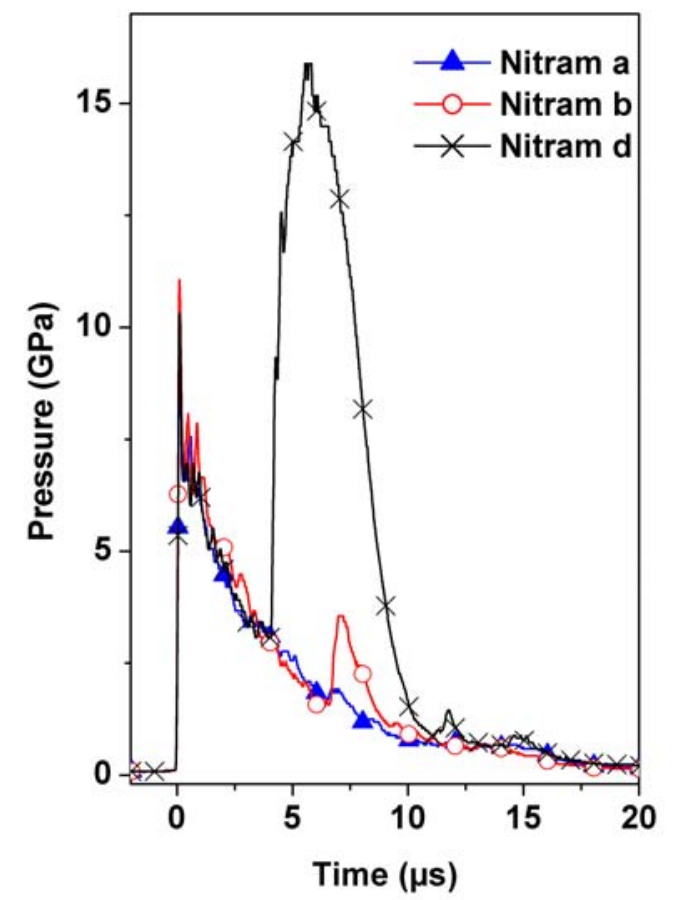

\section{FIGURE 8. PRESSURE MEASUREMENTS FOR TESTED COMPOSITIONS}

\section{DISCUSSION}

The profiles of the pressure and temperature signals are very similar for Nitram (b) and Nitram (d), especially concerning the arrival time of the second maximum. This effect occurs about $5 \mu \mathrm{s}$ after the detonation front. For Nitram (d), the time of arrival of the second maximum is exactly the same for pressure and temperature measurements.

From the analysis of the curves shown in figures 8, 9 and others experiments performed with longer distances between emulsions and pressure sensors, it follows that the second maximum pressure is not a good quantitative pressure value. A perturbation affect the measurement, probably due to the temperature effects on the carbon resistor, related to the Aluminum oxidation. The interface conductivity between the emulsion explosive and the plastic material could interfere with the pressure measurement. So, a simple and low cost method using carbon resistor pressure gauges could be used to identify qualitatively the aluminum heat release in emulsion explosives.

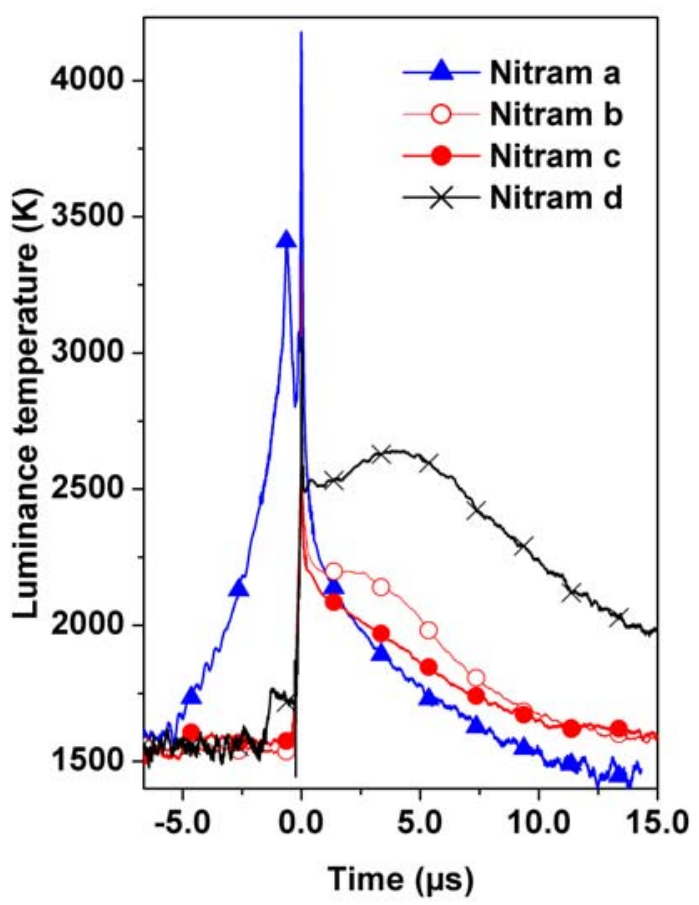

FIGURE 9. LUMINANCE TEMPERATURES FOR THE EMULSION EXPLOSIVES

The presence of the second maximum is explained directly by two opposite heat processes [6], dealing with the interaction between aluminum and the detonation products :

- the heat loss for the preheating of "cold" Al particles by the detonation products, - the heat release of the Al oxidation reaction.

From the analysis of figure 9, the preheating process of the $\mathrm{Al}$ particles last less than $2 \mu \mathrm{s}$ 
after the detonation front. During this preheating process the detonation products temperature of Nitram (d) are higher than Nitram (b) despite a higher Al content for Nitram (d). This is explained by different chemical systems for the two compositions, especially for Nitram (d) which seems to generate more hot detonation products. The $\mathrm{Al}$ content effect is not directly assess in this the preheating process. It should diminish the temperature of the detonation products.

The Al particle size effect on the preheating process is shown less than $2 \mu$ s after the detonation front comparing Nitram (b) and Nitram (c). The temperature of the detonation products is cooled more rapidly for Nitram (c). Coarse Al particle size are more difficult to preheat.

During the heat release process (increase area of the second maximum), the increase of temperature is much higher for Nitram (d), compared to Nitram (b). Despite a different chemical system for the compared compositions, the $\mathrm{Al}$ content effect on the heat release process is identified. A higher content of aluminum is a benefit.

The Al particle size effect on the heat release process is also shown after $2 \mu \mathrm{s}$ after the detonation front comparing Nitram (b) and (c). Fine Al particles, which are preheated faster, release more oxidation energy.

From the analysis of figure 9, the arrival time of the second maximum is longer for Nitram (d) compared to Nitram (b). It seems to be correlated to the previous explanations :

- More time is needed to heat a high content of aluminum,

- More time is required to release more oxidation energy for a high $\mathrm{Al}$ content

- The chemical systems are different, more exothermic for Nitram (d).

The temperature measurements are performed up to $15 \mu \mathrm{s}$ with the interaction of the PMMA windows on the detonation front and detonation products. The calculated total reaction zones are supposed to last few microseconds more, depending of the compositions. So, the total reaction zone could not be assess directly by these tests. Nevertheless, the influence of the Al particle size effect and Al content effect could be estimated from the temperature measurement on a large part of the reaction zone (modified by the reflection of the detonation front with the PMMA window).

The temperature decrease of Nitram (b) is equal to Nitram (c) below $1600 \mathrm{~K}$. Therefore, the Al particle size show no significant effect on the thickness of the total reaction zone, although the heat release is higher for Nitram (b).

Comparing Nitram (d) to Nitram (b), the temperature decrease after the second maximum stay higher for Nitram (d), about $400 \mathrm{~K}$ higher at $15 \mu \mathrm{s}$. Despite a different chemical system for the compared compositions, the $\mathrm{Al}$ content effect seems to have an influence on the total reaction zone.

\section{CONCLUSION}

To sum up, carbon resistor gauges and a large spectral range pyrometer have been presented and validated to measure the detonation pressure and temperature profiles for emulsion explosives.

Four emulsion explosives have been compared by unconfined cylinder tests using these measurements.

A heat release due to the aluminum oxidation is characterized about $5 \mu \mathrm{s}$ after the detonation front, function of the $\mathrm{Al}$ content and the $\mathrm{Al}$ particle size.

The increase of the $\mathrm{Al}$ content and the decrease of the Al particle size show the increase of the heat release on the detonation products. The arrival time of this delayed reaction are also affected by the $\mathrm{Al}$ content and particle size. The total reaction zone seems to be also affected, especially by the Al content.

Work is ongoing on the characterization of Al heat release for other mining industry explosives to improve their compositions and 
to reduce their cost. Combined pressure and temperature measurements are necessary tools to reach such objectives.

\section{REFERENCES}

1. Ginsberg M.J., Asay B.W., Commercial carbon composition resistors as dynamic stress gauges in difficult environments, Rev. Sci. Instrum. 62(9), september 1991

2. R.Saurel, S.Mencacci, S.Mercier, Hydro 3D : un outil simple pour la simulation de problemes de detonique, $25^{\text {th }}$ International Pyrotechnics Seminar, Brest, Europyro 99, juillet 99

3. Léal Crouzet B., Baudin G., Goutelle J-C, Presles H.N., An optical pyrometer for time resolved temperature measurements in detonation wave, $11^{\text {th }}$ International Detonation Symposium, Snowmass, September 1998

4. Léal Crouzet B., "Application de la pyrométrie optique à la mesure de température des produits de réaction d'explosifs condensés en régime d'amorçage et de détonation", Rapport de thèse ENSMA, Octobre 1998

5. Bouyer V., Baudin G., Le Gallic C., Hervé P., Emission spectroscopy applied to shock to detonation transition in nitromethane, APS Topical conference on shock compression of condensed matter, Atlanta, june 2001

6. Gogulya M.F., Dolgoborodov A.Yu., Brazhnikov M.A., Baudin G., Detonation waves in $\mathrm{HMX} / \mathrm{Al}$ mixtures (pressure and temperature measurements), $11^{\text {th }}$ International Detonation Symposium, 1998 